\title{
Oxidative decomposition of methanol in a vibroacoustic fluidized bed of Ag-coated cenosphere core-shell catalyst
}

\author{
Gabriela Berkowicz*, Witold Żukowski, Jerzy Baron \\ Cracow University of Technology, Department of Inorganic Chemistry and Technology, ul. Warszawska 24, \\ 31-155 Cracow, Poland \\ "Corresponding author: e-mail: gberkowicz@chemia.pk.edu.pl
}

\begin{abstract}
The paper presents results of a study of oxidative decomposition of methanol in a fluidized bed of silver catalyst. The process of methanol oxidation was carried out on Ag-coated cenospheres core-shell catalyst. The catalyst was obtained by precipitation of silver from methanolic solution of silver nitrate on cenospheres. Cenospheres are lightweight, inert, hollow spheres, which can be easily introduced into a fluidized bed. Application of the catalyst in a form of fluidized bed should ensure good temperature equalization which is very important at low temperatures due to the possibility of generation of formaldehyde. It turned out that local hot points occur in that kind of a catalyst (in the form of a fluidized bed but with very low density), thus use of additional acoustic wave is necessary to ensure good control over the temperature of the process. The products of the process of methanol oxidation were monitored on-line by Fourier transform infrared spectroscopy (FTIR). The catalyst has proven to be highly active in the oxidative decomposition of methanol. Full of methanol conversion in reaction of complete oxidation was achieved at $350^{\circ} \mathrm{C}$.
\end{abstract}

Keywords: fluidized bed, catalytic oxidation of methanol, silver coated cenospheres.

\section{INTRODUCTION}

Constant industrial development and urbanization make air pollution a serious problem of the modern society ${ }^{\mathbf{1 - 4}}$. Limitation of emissions of volatile organic compounds (VOCs) into the atmosphere is an important step towards improving air quality. VOCs are emitted by a variety of anthropogenic sources ${ }^{6,7}$. The largest countries in the world spend billions of dollars to monitor and control VOC emissions ${ }^{8}$. Methanol belongs to the group of non-methane volatile organic compounds (NMVOC) ${ }^{9}$. Methyl alcohol is widely used as a solvent, inter alia, for the production of coatings, paints and varnishes ${ }^{10}$. Formaldehyde is generated as a result of the partial oxidation of methanol, which has occurred in the atmosphere (due to $\mathrm{OH}$ radicals, among other things $)^{11}$. This aldehyde is classified as highly toxic to human and animals. Formaldehyde is one of the R40 hazards with the symbol $\mathrm{T}$ for toxicity, which means it has carcinogenic effects by inhalation ${ }^{12}$. When polluted air containing methanol is produced during technological processes, methanol should be oxidized to $\mathrm{CO}_{2}$ and $\mathrm{H}_{2} \mathrm{O}$ prior to its emission to the atmosphere taking into account avoid formation of formaldehyde.

Catalytic combustion is one of the most often applied methods of reducing emission of organic pollutants ${ }^{13}$. Thermal decomposition of methanol requires high temperature (typically above $\left.1000^{\circ} \mathrm{C}\right)^{14}$. Application of a catalyst during oxidative decomposition of methanol facilitates reducing the temperature of the process. There are two types of catalysts used in catalytic oxidation: metal oxides and noble metals ${ }^{15}$. Authors of numerous papers show that metals such as platinum, ruthenium, gold and silver are active in the processes of oxidative decomposition of methano ${ }^{16,17}$. In this study, silver was used as the catalyst. Methanol can be adsorbed reversibly on clean Ag. In the presence of pre-adsorbed atomic oxygen during adsorption, however, methanol interacted with surface oxygen through its hydroxyl hydrogen to form methoxy species $\mathrm{CH}_{3} \mathrm{O}_{(\text {a) }}$ and $\mathrm{HO}_{\text {(a) }}$ (reaction 1), where index (a) means species adsorbed at $\mathrm{Ag}$ surface. The interaction between these two adsorbed species can result in the formation of water (reaction 2). $\mathrm{CH}_{3} \mathrm{O}_{(\mathrm{a})}$ species may lead to the creation of formaldehyde (reaction 3) or $\mathrm{CO}_{2}$ (reactions 4 and 5). Hydrogen atoms released in the various reaction steps (reactions 3-5) can be recombined to produce hydrogen ${ }^{18}$.

$$
\begin{aligned}
& \mathrm{CH}_{3} \mathrm{OH}_{(\mathrm{a})}+\mathrm{O}_{(\mathrm{a})} \rightarrow \mathrm{CH} 3 \mathrm{O}_{(\mathrm{a})}+\mathrm{OH}_{(\mathrm{a})} \\
& \mathrm{CH}_{3} \mathrm{OH}_{(\mathrm{a})}+\mathrm{OH}_{(\mathrm{a})} \rightarrow \mathrm{CH}_{3} \mathrm{O}_{(\mathrm{a})}+\mathrm{H}_{2} \mathrm{O}_{(\mathrm{g})} \\
& 2 \mathrm{CH}_{3} \mathrm{O}_{(\mathrm{a})} \rightarrow 2 \mathrm{CH}_{2} \mathrm{O}_{(\mathrm{g})}+2 \mathrm{H}_{(\mathrm{a})} \\
& \mathrm{CH}_{2} \mathrm{O}_{(\mathrm{a})}+\mathrm{O}_{(\mathrm{a})} \rightarrow \mathrm{HCOO}_{(\mathrm{a})}+\mathrm{H}_{(\mathrm{a})} \\
& \mathrm{HCOO}_{(\mathrm{a})} \rightarrow \mathrm{CO}_{2(\mathrm{~g})}+\mathrm{H}_{(\mathrm{a})} \\
& 2 \mathrm{H}_{(\mathrm{a})} \rightarrow \mathrm{H}_{2(\mathrm{~g})}
\end{aligned}
$$

Taking into account that polluted gases often may contain not only gaseous components but also particles of dust, we propose to use fluidized bed as a method of organization of the catalytic process, owing to fact that this type of bed is resistant to dust accumulation. On the other hand, the process of methanol oxidation is exothermic, so good mixing of particles of the catalyst is also an advantage leading to a more uniform temperature profile than in a static catalytic bed.

The primary goal of this study was to find the minimum temperature above which methanol can be completely burnt to $\mathrm{CO}_{2}$ and $\mathrm{H}_{2} \mathrm{O}$. The research focused on finding the lowest temperature; it was therefore vital to control the temperature in the entire volume of the catalytic bed well. The minimum fluidization velocity strongly depends on the density of the particles in the fluidized bed, thus it was decided not to use monolithic grains of silver catalyst in order to achieve lower minimum fluidization velocity. This increased contact time of reactants in the catalytic bed. The ability of the material to fluidize depends on the grain shape, so it was also important to embed the catalyst on a spherical surface.

In this paper, we present a new concept of using cenospheres as a core of a heterogenic catalyst with $\mathrm{Ag}$ as the active component. A diagram of the new type of catalyst 
grain is shown in Figure 1. The cenospheres are a fraction of fly ash generated during combustion of pulverized coal, and can be obtained from solid products of reactions in power plants ${ }^{19}, 20$. Their specific characteristics such as lightness, sphericity and hollowness make the microspheres easy to fluidize. The use of this specific type of material as a catalyst carrier facilitates obtaining a stable catalytic fluidized-bed at low gas velocities. Covering the sphere with silver ensures economical use of the active metal. Indeed, it is known that the catalytic reaction occurs on the catalyst surface, so the center of the grain is not involved in the process. In addition, cenospheres are characterized by high temperature resistance (up to $1300^{\circ} \mathrm{C}$ ), mechanical strength (up to 6 on the Mohs scale) and low thermal conductivity (about $0.07 \mathrm{Wm}-1 \mathrm{~K}-1)^{21,22}$. It is also proposed to carry out the process on a catalyst in a form of fluidized bed to ensure good mass transfer coefficients and temperature equalization in the whole bed of the catalyst. Good temperature equalization is very important in the case of processes carried out at low temperatures due to the possibility of production of formaldehyde. Fluidized bed is also more resistant than packed bed to dust and other pollutant accumulation, which can be present in flue or off-gases being cleaned.

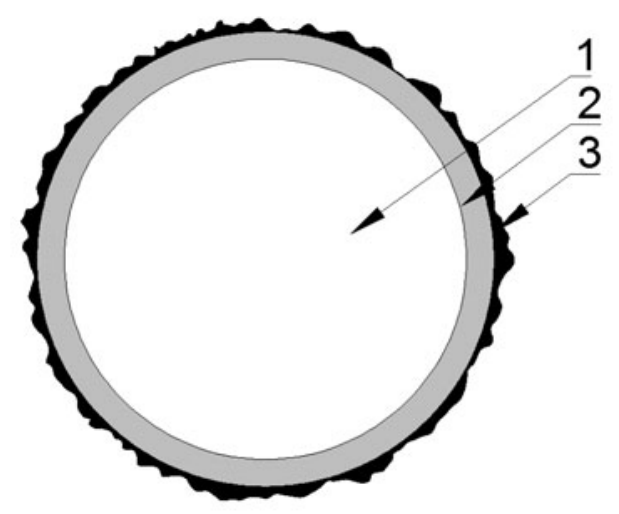

Figure 1. 1-gas-filled interior of cenosphere, 2 - glassy matter (70-100 $\mu \mathrm{m}$ in diameter and $2-5 \mu \mathrm{m}$ in thickness), 3 - silver coating

\section{EXPERIMENTAL PART}

The process of methanol oxidation was carried out in a fluidized bed on Ag-coated cenosphere core-shell catalyst with the weight of $30 \mathrm{~g}$. Silver deposited on the cenospheres with a grain size of $70-100 \mu \mathrm{m}$ was used as the catalyst. It was obtained by precipitation of silver from methanolic solution of silver nitrate on the cenospheres. Glucose was used as the reducing agent, as shown in reaction 7 .



The obtained catalyst contained approx. $2 \%$ of silver by weight. Scanning Electron Microscope image of the prepared catalyst grain is shown in Figure 2. The catalyst was assigned to group A by Geldart's classification (based on the density and particle size $)^{\mathbf{2 3}}$. This kind of catalyst

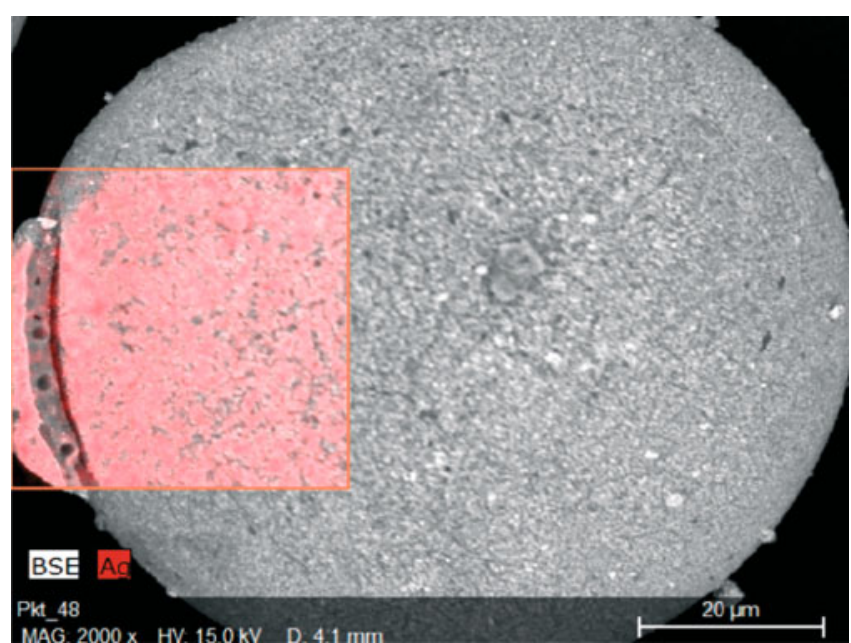

Figure 2. SEM image of silver catalyst coated on a cenosphere

bed should be easy to aerate; have the tendency to form bubbles; and undergo significant expansion.

The catalyst was placed in a tubular flow reactor, which was almost entirely wrapped in a heating spiral. In the standby mode, the ratio of bed height to reactor diameter was 1.7. This parameter is important from the technical point of view. It was noted that a higher ratio carries the risk of channeling and slugging of the fluidized bed. On the other hand, reduction in this ratio leads to a reduction of the contact time of the reactants with the catalyst. An adjustable thermocouple was placed in the catalyst bed. A reactor was mounted on the central outlet of a three-necked round bottom flask. The other two ports of the three-necked flask were used to supply methanol and air at flow rates of $4 \mathrm{ml} / \mathrm{h}$ and 500 $\mathrm{ml} / \mathrm{h}$, respectively. The round bottom flask was placed in a glycerin bath. The temperature of the glycerin was maintained at $120^{\circ} \mathrm{C}$, which provided immediate evaporation of the dosed methanol. This type of dispensing method ensures a steady flow of the two reactants and a stable fluidization state of the catalytic bed. The reaction mixture was appropriately diluted with secondary air stream and directed to the FTIR analyzer equipped with a heated gas cuvette. Diagram of the laboratory installation is shown in Figure 3.

Methanol conversion was investigated in the temperature range of $200-360^{\circ} \mathrm{C}$. Products of combustion of the alcohol were continuously monitored by the FTIR analyzer. The duration of a single analysis was 20 seconds. Analyses followed successively one after the other. The temperature of the catalytic fluidized bed was being steadily raised and lowered with a programmable temperature controller (RE72 by LUMEL) at a rate not exceeding $5^{\circ} \mathrm{C} / \mathrm{min}$. Methanol, formaldehyde, methane, ethane, propane, acetylene, carbon monoxide and carbon dioxide, dimethyl ether, acetone and formic acid were selected as the monitored components in the FTIR analysis of the process of oxidative decomposition of methanol.

\section{RESULTS}

The volumetric flow of methanol $(4 \mathrm{ml} / \mathrm{h})$ was controlled by a medical infusion pump (by ASCOR). In turn, the volumetric flow of air $(500 \mathrm{ml} / \mathrm{h})$ was controlled by gas flow mass controller series GFC (by DWYER). 




1 - air, 2-glycerin bath, 3 - FT-IR, 4 - PID temperature regulator RE72, 5 - regulatory thermocouples, 6 - set of temperature regulation, 7 - heating spiral, 8 - methanol, 9 - catalytic bed

Figure 3. Experimental set-up for continuous monitoring of products of oxidative methanol decomposition in the catalytic fluidized bed of silver catalyst coated on cenospheres

This method of dispensing meant that $98.59 \mathrm{mmol} / \mathrm{h}$ of $\mathrm{CH}_{3} \mathrm{OH}$ and $281.25 \mathrm{mmol} / \mathrm{h}$ of $\mathrm{O}_{2}$ were fed to the reactor. The conversion of volumetric flows into molar flows is useful because it facilitates the direct estimation of the efficiency of the process monitored by the FTIR analyzer. The molar flows of the main components of the reaction mixture, changing with the temperature during heating and cooling of the catalytic bed, were shown in Figure 4. The graph illustrates values for the main products: methanol, formaldehyde and $\mathrm{CO}_{2}$ obtained during heating and cooling of the bed. Other registered streams that were not shown in the diagram, hydrocarbons did not exceed $5 \mathrm{mmol} / \mathrm{h}$. The slight discontinuities at around $240^{\circ} \mathrm{C}$ and $280^{\circ} \mathrm{C}$ probably result from the imperfections of the dosing method, which is related to dispensing at very low flow rates. The standard errors of the FTIR method should not exceed 5\% (relative error).

It was noted that during cooling that the reactor substrate conversion did not change in the expected man-

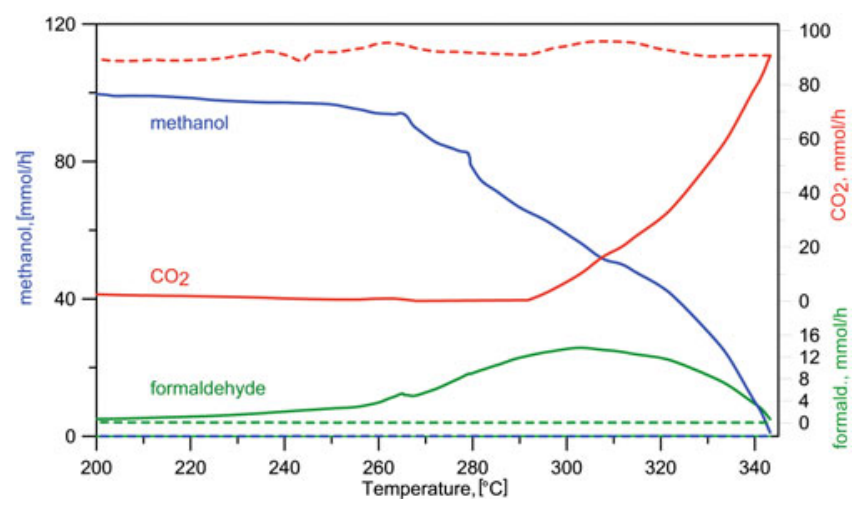

Figure 4. Streams of the main components of the reaction mixture as a function of temperature recorded during the oxidative decomposition of methanol in a fluidized bed of silver catalyst deposited on cenospheres. Continuous line and dotted relate to data obtained during the increase and decrease of temperature, respectively. Other streams (not shown in the diagram) of hydrocarbons were not greater than $5 \mathrm{mmol} / \mathrm{h}$ ner that would reflect the changes observed during the increase of the temperature in the reactor. Exothermic reactions take place with great intensity in the catalyst bed. It means that hot spots exist even in the fluidized bed. In these hot areas, the temperature is higher than the average temperature in the bed, and the degree of conversion of methanol is greater there. It is possible in the case of exothermic processes, and is unfavorable from the technological point of view because lack of proper control over the temperature of the catalyst in the whole reactor volume can lead to inappropriate course of the reactions and cause premature catalyst deactivation.

The results indicative of the existence of this situation are shown in Figure 4. The graph illustrates values of the main product stream obtained during heating and cooling of the bed. The catalyst has proven to be highly active in the tested temperature range. Formation of formaldehyde was observed at $240-340^{\circ} \mathrm{C}$, but the highest obtained concentration of formaldehyde was achieved for only $14 \%$ of the potential yield of this compound. An increase in the temperature of the bed above $290^{\circ} \mathrm{C}$ results in methanol being converted intensely to $\mathrm{CO}_{2}$. $\mathrm{CO}$ was not recorded in the exhaust gases. Conversion of methanol to $\mathrm{CO}_{2}$ and other products reached $100 \%$ at temperatures above $340^{\circ} \mathrm{C}$. At this temperature, almost all of the carbon has reacted to $\mathrm{CO}_{2}$. As can be seen in the graph in Figure 4, methanol conversion during bed cooling was not decreasing in a way corresponding to the data obtained while the temperature was increasing.

An analogous process of methanol oxidation on a catalytic fluidized bed supported by vibroacoustic technology with acoustic waves at the frequency of $45 \mathrm{~Hz}$ was conducted to intensify the heat exchange by convection (between the grain and the gas) and conduction (between particles of the fluidized bed). This has resulted in a significant improvement in the fluidization process. The results of the experiment are shown in an analogous to the previous process diagram in Figure 5. Hydrodynamic properties of the catalytic bed at a particular temperature are shown in Table 1. 


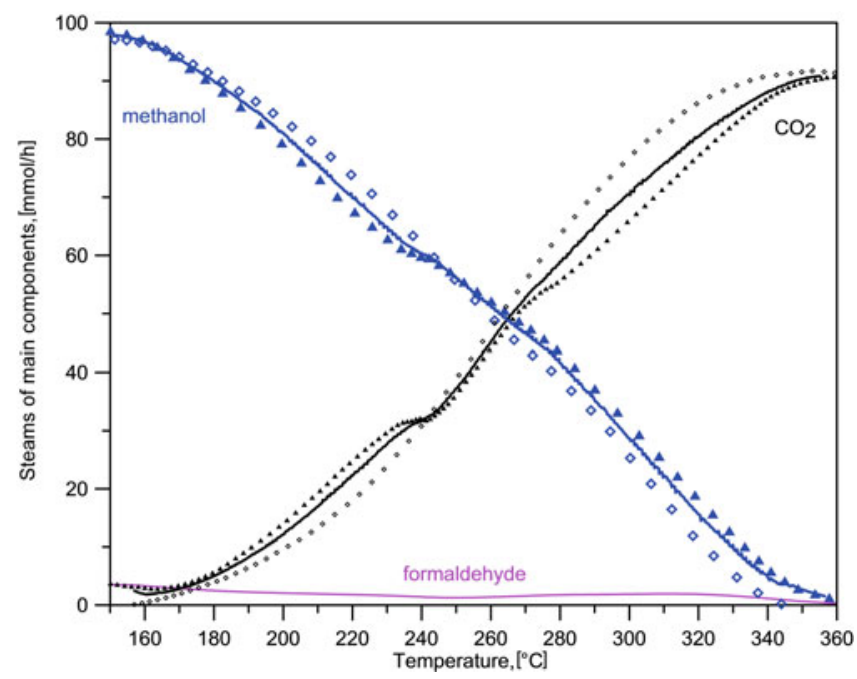

Figure 5. Streams of the main components of the reaction mixture as a function of temperature monitored during the oxidative decomposition of methanol in a fluidized bed of silver catalyst deposited on cenospheres supported by vibroacustics. Filled triangles and empty diamonds denote data obtained during the increase and decrease of temperature, respectively. Solid line denote mean values at given temperature

Table 1. Hydrodynamic properties of catalytic bed at a particular temperature

\begin{tabular}{|c|c|c|}
\hline Temperature, $\left[{ }^{\circ} \mathrm{C}\right]$ & $160^{\circ} \mathrm{C}$ & $350^{\circ} \mathrm{C}$ \\
\hline Mass of bed, [g] & \multicolumn{2}{|c|}{30.0} \\
\hline Grain size, $[\mu \mathrm{m}]$ & \multicolumn{2}{|c|}{$70-100$} \\
\hline $\begin{array}{l}\text { Density of grains, } \\
{\left[\mathrm{g} / \mathrm{cm}^{3}\right]}\end{array}$ & \multicolumn{2}{|c|}{0.86} \\
\hline $\begin{array}{l}\text { Height of stationary } \\
\text { bed, }[\mathrm{cm}]\end{array}$ & \multicolumn{2}{|c|}{6} \\
\hline Acoustic waves, $[\mathrm{Hz}]$ & \multicolumn{2}{|c|}{45} \\
\hline $\begin{array}{l}\text { Minimum fluidization } \\
\text { velocity, }[\mathrm{cm} / \mathrm{s}]\end{array}$ & 0.187 & 0.142 \\
\hline $\begin{array}{l}\text { Terminal velocity, } \\
{[\mathrm{cm} / \mathrm{s}]}\end{array}$ & 15.487 & 12.213 \\
\hline $\begin{array}{l}\text { Processing gas } \\
\text { velocity, }[\mathrm{cm} / \mathrm{s}]\end{array}$ & 1.026 & 1.073 \\
\hline Fluidization number & 5.5 & 7.5 \\
\hline
\end{tabular}

Application of vibroacoustics removed the local hot spots, as evidenced by the similarity of data obtained during the increase and decrease of temperature. The FTIR analysis of the composition of the reaction mixture, which passed through the bed supported with vibrations indicated on only trace amounts of the analyzed hydrocarbons $(<5 \mathrm{mmol} / \mathrm{h})$. On such a bed, it is possible to carry out the process mainly towards the total combustion of methanol.

Formaldehyde formation in the fluidized bed assisted by vibrations also decreased and this is also evidence of intensification of not only the heat exchange processes but also the mass transfer between gas phase and catalyst surface.

\section{CONCLUSIONS}

The heterogeneous, core-shell catalyst obtained by precipitation of silver on the cenospheres has proven to be highly active in the oxidative decomposition of methanol. It is possible to achieve $100 \%$ conversion of methanol in reaction of complete combustion of alco- hol to $\mathrm{CO}_{2}$ and $\mathrm{H}_{2} \mathrm{O}$ (according to reaction set 1-6), at temperature as low as $350^{\circ} \mathrm{C}$.

One of the primary advantages of using the catalytic material in the fluidized state is very good equalization of the temperature in the entire volume of the bed. It turns out, however, that fluidization on its own may not be sufficient to obtain good temperature equalization for material that has very low density. For that kind of material, it is preferred to support the fluidization by using vibration, which changes hydrodynamics of the fluidized state and eliminates local hot spots in the bed.

\section{LITERATURE CITED}

1. World Health Organization. (2016). Air Quality. Data and statistics. http://www.euro.who.int/en/health-topics/environment-and-health/air-quality/data-and-statistics, access on date 2016-04-21.

2. Samet, J.M. \& Cohen, A.J. (1999). Air pollution and lung cancer. In: Holgate S.T., Samet J.M., Koren, H.S., Maynard, R.L,. eds. Air Pollution and Health. San Diego, CA: Academic Press, 841-864.

3. Jedrychowski, W., Becher, H., Wahrendorf, J. \& BasaCierpialek, Z. (1990). A case-control study of lung cancer with special reference to the effect of air pollution in Poland. J. Epidemiol Com. Health, 44, 114-120. DOI: 10.1136/ jech.44.2.114.

4. Vena, J.E. (1982). Air pollution as a risk factor in lung cancer. Am. J. Epidemiol. 116, 42-56.

5. Directive 2004/42/CE of the European Parliament and of the Council of 21 April 2004 on the limitation of emissions of volatile organic compounds due to the use of organic solvents in certain paints and varnishes and vehicle refinishing products and amending Directive 1999/13/EC http://eur-lex.europa.eu/ legal-content/EN/TXT/?uri=CELEX:32004L0042, access on date 2016-04-21.

6. Sahu, L.K., Yadav, R. \& Pal, D. (2016). Source identification of VOCs at an urban site of western India: Effect of marathon events and anthropogenic emissions, J. Geophys. Res. Atmos., 121(5) 2416-2433. DOI: 10.1002/2015JD024454.

7. Sahu, L.K. \& Saxena, P. (2015). High time and mass resolved PTR-TOF-MS measurements of VOCs at an urban site of India during winter: role of anthropogenic, biomass burning, biogenic and photochemical sources. Atmos. Res., 164, 84-94. DOI: $10.1016 /$ j.atmosres.2015.04.021.

8. Kołodziej, A., Łojewska, J. \& Kleszcz, T. (2007). Structured catalytic reactor for VOC combustion. Pol. J. Chem. Technol. 9(1), 10-14. DOI: 10.2478/v10026-007-0004-0.

9. The National Centre for Emissions Management (KOBiZE)(in Polish: Krajowy Ośrodek Bilansowania i Zarządzania Emisjami, (2012). Material for the regulation and the requirements for balancing emissions of non-methane Volatile Organic Compounds (in Polish: Materiał dotyczący regulacji oraz wymagań w zakresie bilansowania emisji Niemetanowych Lotnych Związków Organicznych (NMLZO) ), https://krajowabaza.kobize.pl/docs/NMLZO-21-12-2012.pdf, access on date 2016-04-21.

10. Cheng, W.H. \& Kung, H.H. (1994). Methanol Production and Use. New York, Marcel Dekker INC.

11. Reuss, G., Disteldorf, W., Gamer, A.O., Hilt, A. (2000). Formaldehyde, Ullmann's Encyclopedia of Industrial Chemistry. DOI: 10.1002/14356007.a11_619.

12 Sigma-Aldrich, (2016). Safety Data Sheet of Formaldehyde. http://www.sigmaaldrich.com/MSDS/MSDS/DisplayMSDSPage. do country $=$ PL\&language $=$ pl\&productNumber $=252549 \&$ bra nd=SIAL, access on date 2016-04-21.

13. Parus, W.J. \& Paterkowski, W. (2009). Catalytic oxidation of organic pollutants. Pol. J. Chem. Technol. 11(4) 30-37. DOI: 10.2478/v10026-009-0040-z. 
14. Lee, P.F., Matsui, H., Xu, D.W. \& Wang, N.S. (2013). Thermal Decomposition and Oxidation of $\mathrm{CH} 3 \mathrm{OH}$. J. Phys. Chem. A, 117, 525-534. DOI: 10.1021/jp309745p.

15. Tsou, J., Magnoux, P., Guisnet M., Órfao, J.J.M. \& Figueiredo, J.L. (2005). Catalytic oxidation of volatile organic compounds. Oxidation of methyl-isobutyl-ketone over Pt/zeolite catalysts. Appl Catal B Environ 57, 117-123. DOI: 10.1016/j. apcatb.2004.10.013.

16. Shimoda, N., Umehara, S., Kasahara, M., Hongo, T., Yamazaki, A. \& Satokawa, S. (2015). Methanol oxidative decomposition over zirconia supported silver catalyst and its reaction mechanism. Appl. Catal. Gen. 507, 56-64. DOI: 10.1016/j.apcata.2015.09.017.

17. Borasio, M., Rodriguez de la Fuente O., Rupprechter, G. \& Freund H.J. (2005). In Situ Studies of Methanol Decomposition and Oxidation on Pd(111) by PM-IRAS and XPS Spectroscopy. J. Phys. Chem. B, 109(38), 17791-17794. DOI: $10.1021 / \mathrm{jp} 053855 \mathrm{c}$.

18. Waterhouse, G.I.N., Bowmaker, G.A. \& Metson, J.B. (2004). Mechanism and active sites for the partial oxidation of methanol to formaldehyde over an electrolytic silver catalyst, Appl. Catal. Gen. 265(1), 85-101. DOI: 10.1016/j. apcata.2004.01.016.

19. Anshits, N.N., Mikhailova O.A., Salanov A.N. \& Anshits A.G. (2010). Chemical composition and structure of the shell of fly ash non-perforated cenospheres produced from the combustion of the Kuznetsk coal (Russia). Fuel 89(8), 1849-1862. DOI: 10.1016/j.fuel.2010.03.049.

20. Bradło, D., Żukowski, W., Czupryński, P. \& Witkowski, K. (2014). Acquisition and choice of method for fractionation of cenospheres from fly ashes. Przem. Chem. 93(7), 1114-1117. DOI: 10.12916/przemchem.2014.1114. (in Polish)

21. Kruger, R.A. (1996). The Use of Cenospheres in Refractories. Energeia, Center Appl. Ener. Res. 7, 4. http://www. caer.uky.edu/energeia/pdf/vol7-4.pdf

22. Elpologistyka Sp. z o.o., Raport z badań mikrosfery, http://www.elpologistyka.pl/wp-content/uploads/2015/11/Raport-z-badan-mikrosfery1.pdf, access on date 2016-04-21.

23. Geldart, D. (1973). Types of Gas Fluidization. Pow. Tech., 7, 285-292. DOI: 10.1016/0032-5910(73)80037-3. 